\title{
Prognostic value of lymph node ratio in patients with small-cell carcinoma of the cervix based on data from a large national registry
}

Juan Zhou, ${ }^{1, *}$ Jia-Yuan

Sun, ${ }^{2, *}$ Shan-Yu Chen, ${ }^{3}$

Feng-Yan Li, ${ }^{2}$ Huan-Xin Lin, ${ }^{2}$

San-Gang Wu, ${ }^{3}$ Zhen-Yu He ${ }^{2}$

'Department of Obstetrics and Gynecology, Xiamen Cancer Center,

The First Affiliated Hospital

of Xiamen University, Xiamen,

${ }^{2}$ Department of Radiation Oncology,

Sun Yat-sen University Cancer

Center, State Key Laboratory

of Oncology in South China,

Collaborative Innovation Center

of Cancer Medicine, Guangzhou,

${ }^{3}$ Department of Radiation Oncology,

Xiamen Cancer Center, The First

Affiliated Hospital of Xiamen

University, Xiamen, People's Republic

of China

*These authors contributed equally to this work

Correspondence: San-Gang Wu Department of Radiation Oncology,

Xiamen Cancer Center, The First

Affiliated Hospital of Xiamen University,

55 Zhenhai Road, Xiamen 361003, Fujian,

People's Republic of China

Tel +865922139531

Fax +86592 213 7301

Email unowu12345@hotmail.com

Zhen-Yu He

Department of Radiation Oncology, Sun Yat-sen University Cancer Center, State Key Laboratory of Oncology in South

China, Collaborative Innovation Center of Cancer Medicine, 65I Dongfeng

Road East, Guangzhou 510060, People's

Republic of China

Tel +862087343543

Fax +862087343392

Email hezhy@sysucc.org.cn
This article was published in the following Dove Press journal:

OncoTargets and Therapy

23 December 2015

Number of times this article has been viewed

Objective: To investigate the prognostic value of the lymph node ratio (LNR) in patients with small-cell carcinoma of the cervix (SCCC) after cancer-directed surgery using a populationbased national registry (Surveillance Epidemiology and End Results [SEER]).

Methods: We retrospectively reviewed the data of SCCC patients in the SEER database from 1980 to 2012. The prognostic impact of LNR with respect to cause-specific survival (CSS) and overall survival (OS) was analyzed.

Results: A total of 118 patients with SCCC were identified. The median follow-up was 30.5 months. All these patients were treated with cancer-directed surgery and lymphadenectomy. Sixty (50.8\%) patients had nodal metastases. The median LNR was 0.16 in patients with positive lymph nodes. Univariate analysis showed that prognostic factors such as International Federation of Gynecology and Obstetrics (FIGO) stage, nodal status, LNR, and local treatment modalities affected CSS and OS $(P<0.05)$. Multivariate analysis showed that LNR was an independent prognostic factor for CSS and OS. Patients with a higher LNR had worse CSS (hazard ratio [HR]: 8.832; 95\% confidence interval [CI]: 3.762-20.738; $P<0.001$ ) and OS (HR: 8.462; 95\% CI: $3.613-19.821 ; P<0.001)$. LNR was associated with CSS and OS by stage, especially in FIGO stage I-II patients.

Conclusion: LNR is an independent prognostic factor in SCCC patients and it may help to individualize adjuvant therapy.

Keywords: small-cell carcinoma of the cervix, SEER, lymph node ratio, lymph node, prognostic factors

\section{Introduction}

Small-cell carcinoma of the cervix (SCCC) is a rare type of cervical cancer that comprises $\sim 2 \%-5 \%$ of all cervical cancers. SCCC is highly aggressive and rapidly leads to lymphogenous and hematogenous metastases. ${ }^{1-3}$ Prognostic factors impacting survival in patients with SCCC include the International Federation of Gynecology and Obstetrics (FIGO) stage, age, depth of interstitial infiltration, tumor size, chromogranin A status, and the extent of lymph node involvement. However, as SCCC is a rare form of cervical cancer, the prognostic values of these factors in SCCC are still controversial. ${ }^{4-7}$

Recent studies have shown that SCCC patients show a higher rate of lymph node involvement (range: $39.4 \%-70 \%$ ) than cervical squamous cell carcinoma patients or patients with cervical adenocarcinoma. ${ }^{6-10}$ Studies have also shown that lymph node status is an important factor in determining prognosis in SCCC patients. However, due to the small sample size in these studies, no consensus has been reached regarding 
the prognostic value of lymph node status in SCCC. Although lymph node status closely correlates to the number of resected lymph nodes (RLNs) in patients, nevertheless, inadequate lymphadenectomy may result in an inaccurate assessment of lymph nodes status and affect the subsequent choice of adjuvant therapy.

Currently, the optimal number of RLNs during lymphadenectomy in cervical cancer remains unclear. However, the lymph node ratio (LNR) (ie, the ratio of the number of positive lymph nodes to the number of RLNs) has been shown to be a prognostic factor in cervical, endometrial, and ovarian cancers. ${ }^{11-18}$ Thus, LNR may more accurately reflect the nodal status. However, there have been no studies investigating the potential effects of the LNR on prognosis in SCCC. Therefore, we performed a retrospectively analysis of 118 SCCC patients - who had undergone cancer-directed surgery (CDS) - from Surveillance Epidemiology and End Results (SEER) database to determine the prognostic value of LNR in SCCC patients.

\section{Patients and methods Definition of SCCC patients}

Data were obtained from the current SEER database (Surveillance Research Program, National Cancer Institute SEER*Stat software [version 8.2.1], http://www.seer.cancer. gov/seerstat) maintained by the National Cancer Institute, which consists of 18 population-based cancer registries. We obtained permission to access research data files with the reference number 11252-Nov 2014. ${ }^{19}$ Pathologic diagnosis was based on the primary tumor site using the International Classification of Disease for Oncology, third edition (ICD-O-3). Use of the SEER database data does not require informed consent, and this study was approved by the ethics committee of the First Affiliated Hospital of Xiamen University and Sun Yat-sen University Cancer Center.

Patients with a diagnosis of SCCC were identified from 1980 to 2012 using the SEER database. SCCC patients who received both $\mathrm{CDS}$ and lymphadenectomy, without receiving preoperative radiotherapy, and whose lymph node status was known, including the number of positive lymph nodes and the total number of RLNs, were included in the study.

\section{Clinicopathologic factors}

The clinical and pathologic factors collected from the SEER database included age at diagnosis, race, marital status, sex, FIGO stage, grade, tumor size, nodal status, LNR, and local treatment modalities including surgery with and without radiotherapy. Vital status, including the cause of death, and the duration of follow-up were also recorded.

\section{Statistical analysis}

The $\chi^{2}$ and Fisher's exact probability tests were used to analyze the differences between qualitative data. Cutoff point analyses were then performed to determine whether or not there was an LNR cutoff related to the greatest difference in cause-specific survival (CSS) and overall survival (OS). The optimum cutoff point for LNR was determined using the receiver operating characteristic (ROC) curve. Univariate and multivariate Cox regression analyses were used to analyze risk factors for CSS and OS. Multivariable analyses were used to determine the factors that were significantly associated with CSS and OS on univariate analyses. Calculation of survival rates was plotted using the Kaplan-Meier method and compared using the log-rank test. All data were analyzed using the SPSS statistical software package, version 21.0 (IBM Corporation, Armonk, NY, USA). A value of $P<0.05$ was considered statistically significant.

\section{Results}

\section{Patient characteristics and treatment}

Data of 118 eligible patients with SCCC were retrospectively analyzed. Table 1 summarizes the characteristics of the study population. The median age at diagnosis was 37 years (range: $23-85$ years). Of the 116 patients whose FIGO stage was available, $64.7 \%$ of patients $(75 / 116)$ were found to be at stage I, $18.1 \%$ of patients $(21 / 116)$ at stage II, $5.2 \%$ of patients (6/116) at stage III, and $12.1 \%$ of patients (14/116) at stage IV. Of the 96 patients whose histologic grade was available, $96.9 \%$ of the patients $(93 / 96)$ had poorly or undifferentiated histology.

All patients were treated with CDS and lymphadenectomy, and $50.0 \%(59 / 118)$ of the patients received CDS combined with radiotherapy. Of them, 49.2\% (58/118) were node negative and $50.8 \%(60 / 118)$ had nodal metastases. The median number of positive lymph nodes was 2 (range: 1-17) in node-positive patients and the median LNR was 0.16 (range: $0.02-1.0)$.

\section{Analysis of prognostic factors}

Univariate analysis showed that prognostic factors such as FIGO stage, nodal status, LNR, and local treatment modalities affected CSS and OS $(P<0.05)$ (Table 2). Age, race, marital status, and tumor size had no effect on CSS and OS $(P>0.05)$. 
Table I Patient characteristics

\begin{tabular}{|c|c|}
\hline Variables & $\mathbf{n}$ \\
\hline \multicolumn{2}{|l|}{ Age (years) } \\
\hline Median (range) & $37(23-85)$ \\
\hline $19-29$ & 26 \\
\hline $30-39$ & 39 \\
\hline $40-49$ & 22 \\
\hline $50-59$ & 18 \\
\hline $60-69$ & 9 \\
\hline $70-79$ & 2 \\
\hline $80+$ & 2 \\
\hline \multicolumn{2}{|l|}{ Race } \\
\hline Black & 10 \\
\hline White & 89 \\
\hline Other & 19 \\
\hline \multicolumn{2}{|l|}{ Marital status } \\
\hline No & 50 \\
\hline Yes & 68 \\
\hline \multicolumn{2}{|l|}{ FIGO stage $(n=1 \mid 6)$} \\
\hline I & 75 \\
\hline II & 21 \\
\hline III & 6 \\
\hline IV & 14 \\
\hline \multicolumn{2}{|l|}{ Grade $(n=96)$} \\
\hline Well/moderately differentiated & 3 \\
\hline Poorly/undifferentiated & 93 \\
\hline \multicolumn{2}{|l|}{ Tumor size $(\mathrm{cm})(\mathrm{n}=90)$} \\
\hline$<2$ & 6 \\
\hline $2-4$ & 68 \\
\hline$>4$ & 16 \\
\hline \multicolumn{2}{|l|}{ Nodal status } \\
\hline Node negative & 58 \\
\hline Node positive & 60 \\
\hline \multicolumn{2}{|l|}{ Lymph node ratio } \\
\hline Median (range) & $0.16(0.02-1.0)$ \\
\hline \multicolumn{2}{|l|}{ Local treatment modalities } \\
\hline Surgery & 59 \\
\hline Surgery + radiotherapy & 59 \\
\hline
\end{tabular}

Abbreviation: FIGO, International Federation of Gynecology and Obstetrics.

Multivariate analysis showed that LNR was an independent prognostic factor for CSS and OS. Patients with a higher LNR had worse CSS (hazard ratio [HR]: 8.832; 95\% confidence interval $[\mathrm{CI}]$ : 3.762-20.738; $P<0.001)$ and OS (HR: 8.462 ; 95\% CI: 3.613-19.821; $P<0.001$ ) (Table 3).

\section{Identification of optimal cutoff points of LNR}

The optimal cutoff points of LNR were analyzed in nodepositive patients using ROC curve. The results showed that 0.17 was the optimal LNR cutoff point for CSS (area under ROC curve $=0.680 ; P=0.001$ ) and OS (area under ROC curve $=0.677 ; P=0.001)$. Thus, the optimal cutoff value of
0.17 was validated as a prognostic factor for analyzing the clinical effect of LNR (Figure 1A and B).

\section{Impact of LNR on survival}

The median follow-up time was 30.5 months (range: 4-250 months). The 1-, 3-, and 5-year CSS were $81.7 \%$, $56.4 \%$, and $49.5 \%$, respectively (Figure $2 \mathrm{~A}$ ). The 1-, 3-, and 5 -year OS were $81.7 \%, 55.5 \%$, and $47.8 \%$, respectively (Figure 2B).

Based on the LNR, the 5-year CSS in patients with LNR of $0,0.01-0.17$, and $>0.17$ were $62.7 \%, 53.6 \%$, and $19.8 \%$, respectively $(P<0.001)$. The 5 -year OS in patients with LNR of $0,0.01-0.17$, and $>0.17$ were $60.9 \%, 50.4 \%$, and $19.8 \%$, respectively $(P<0.001)$ (Figure 3$)$.

The prognostic effect of LNR according to FIGO stage was also examined. In patients with FIGO stage I-II, the LNR was significantly associated with CSS ( $\log \operatorname{rank} P=0.002)$ and OS (log rank $P=0.003$ ) (Figure 4). As the number of patients $(\mathrm{N}=20)$ with FIGO stage III-IV was limited, no association of LNR with CSS (log rank $P=0.155)$ or OS $(P=0.155)$ was observed.

\section{Discussion}

In this study, we investigated the prognostic value of the LNR in SCCC patients based on the data collected from the SEER database, and the results showed that LNR was an independent prognostic factor that affected the survival rate in SCCC patients.

Currently, the prognostic value of lymph node status in SCCC is still controversial. Wang et al found that lymph node status was an independent prognostic factor for survival in SCCC patients. ${ }^{7}$ Liao et al also reported similar results using univariate analysis; however, no significant difference was found when multivariate analysis was conducted. ${ }^{6}$ Other studies have shown that lymph node status had no prognostic value for SCCC. ${ }^{4,8}$ The number of patients that can be studied is often limited by the rarity of the disease. In this study, we analyzed the data of 118 SCCC patients from the SEER database; of them $50.8 \%$ had nodal metastases, which was consistent with the rates of $39.4 \%-70 \%$ found in other studies, ${ }^{6-8}$ and it was significantly higher than the rate of positive lymph nodes found in cervical squamous cell carcinoma and cervical adenocarcinoma. ${ }^{9,10}$ These results indicated that the lymph node status in SCCC patients was worthy of further investigation.

The staging of SCCC is still referenced to the staging system used in cervical cancer. Lymph node status is not considered in the FIGO staging system. ${ }^{20}$ In the seventh 
Table 2 Univariate analysis of cause-specific survival and overall survival

\begin{tabular}{|c|c|c|c|c|c|c|}
\hline \multirow[t]{2}{*}{ Variables } & \multicolumn{3}{|l|}{ CSS } & \multicolumn{3}{|l|}{ OS } \\
\hline & HR & $95 \% \mathrm{Cl}$ & $P$-value & HR & $95 \% \mathrm{Cl}$ & $P$-value \\
\hline Age (years) (continuous variable) & 0.993 & $0.972-1.013$ & 0.476 & 0.995 & $0.975-1.015$ & 0.613 \\
\hline \multicolumn{7}{|l|}{ Race } \\
\hline Black & 1 & & & 1 & & \\
\hline White & 0.767 & $0.325-1.807$ & 0.544 & 1.353 & $0.48 \mathrm{I}-3.804$ & 0.566 \\
\hline Other & 0.579 & $0.194-1.722$ & 0.326 & 1.033 & $0.502-2.127$ & 0.929 \\
\hline \multicolumn{7}{|l|}{ Marital status } \\
\hline No & I & & & I & & \\
\hline Yes & 0.804 & $0.47 I-1.373$ & 0.425 & 0.860 & $0.508-1.457$ & 0.575 \\
\hline \multicolumn{7}{|l|}{ FIGO stage } \\
\hline I & 1 & & & I & & \\
\hline$\|$ & 1.668 & $0.866-3.211$ & 0.126 & 1.567 & $0.819-2.997$ & 0.175 \\
\hline III & 3.335 & $1.160-9.588$ & 0.025 & 3.169 & I.107-9.07| & 0.032 \\
\hline IV & 1.659 & $0.726-3.791$ & 0.230 & 1.554 & $0.684-3.532$ & 0.293 \\
\hline \multicolumn{7}{|l|}{ Tumor size $(\mathrm{cm})$} \\
\hline$<2$ & 1 & & & I & & \\
\hline $2-4$ & 0.926 & $0.426-2.012$ & 0.845 & 0.869 & $0.413-1.827$ & 0.711 \\
\hline$>4$ & 0.590 & $0.244-1.427$ & 0.242 & 0.525 & $0.222-1.240$ & 0.142 \\
\hline \multicolumn{7}{|l|}{ Nodal status } \\
\hline Node negative & 1 & & & 1 & & \\
\hline Node positive & 2.058 & $1.176-3.600$ & 0.011 & 2.011 & $1.163-3.477$ & 0.012 \\
\hline LNR (continuous variable) & 8.898 & $3.935-20.118$ & $<0.00$ I & 8.562 & $3.795-19.316$ & $<0.00$ I \\
\hline \multicolumn{7}{|l|}{ Local treatment modalities } \\
\hline Surgery & I & & & I & & \\
\hline Surgery + radiotherapy & 1.900 & $1.083-3.333$ & 0.025 & 1.866 & $1.076-3.234$ & 0.026 \\
\hline
\end{tabular}

Abbreviations: CSS, cause-specific survival; OS, overall survival; LNR, lymph node ratio; HR, hazard ratio; Cl, confidence interval; FIGO, International Federation of Gynecology and Obstetrics.

edition of the American Joint Committee on Cancer (AJCC)/ Union for International Cancer Control (UICC) staging system, the stage of cervical cancer is primarily determined by the presence of a positive lymph node. Patients with lymph node-positive cancer will be staged as IIIb. ${ }^{21}$ The method for nodal staging in AJCC/UICC staging system is simple but the results are affected by the total number of RLNs. The nodal staging may be underestimated due to inadequate lymph node sampling. In this study, the prognostic value of LNR was better than the nodal staging. Thus, LNR may provide an accurate reflection of the lymph nodes status of the SCCC patients. The use of LNR is easy, and it assists in the choice of adjuvant treatment and evaluation of the prognosis of patients in the clinical setting. ${ }^{22}$ LNR also reduces the influence of level differences on different surgeons and pathologists. ${ }^{23}$

The LNR has been used to predict prognosis in patients with breast, esophageal, colorectal, and gastric cancers. ${ }^{24-29}$ It is also a prognostic factor in gynecological malignancies, including ovarian cancer and endometrial cancer. ${ }^{11-13}$ Several studies have indicated the usefulness of the LNR in predicting prognosis in cervical cancer patients. ${ }^{14-18}$ However, no relevant study has confirmed the prognostic value of LNR in SCCC. This study is important because it is the first to assess the prognostic value of LNR relative to current lymph node staging among patients with SCCC.

In the subgroup analysis, we also found that LNR had prognostic value in FIGO stage I-II patients but not in

Table 3 Multivariate analyses of cause-specific survival and overall survival

\begin{tabular}{|c|c|c|c|c|c|c|}
\hline \multirow[t]{2}{*}{ Variables } & \multicolumn{3}{|l|}{ CSS } & \multicolumn{3}{|l|}{ OS } \\
\hline & HR & $95 \% \mathrm{Cl}$ & $P$-value & HR & $95 \% \mathrm{Cl}$ & $P$-value \\
\hline FIGO stage & 1.064 & $0.797-|.42|$ & 0.674 & 1.039 & $0.779-1.385$ & 0.796 \\
\hline Nodal status & 1.074 & $0.522-2.213$ & 0.846 & 1.085 & $0.536-2.198$ & 0.820 \\
\hline LNR (continuous variable) & 8.832 & $3.762-20.738$ & $<0.001$ & 8.462 & $3.613-19.821$ & $<0.001$ \\
\hline Local treatment modalities & 1.535 & $0.816-2.889$ & 0.184 & 1.492 & $0.803-2.772$ & 0.205 \\
\hline
\end{tabular}

Abbreviations: CSS, cause-specific survival; OS, overall survival; LNR, lymph node ratio; HR, hazard ratio; Cl, confidence interval; FIGO, International Federation of Gynecology and Obstetrics. 

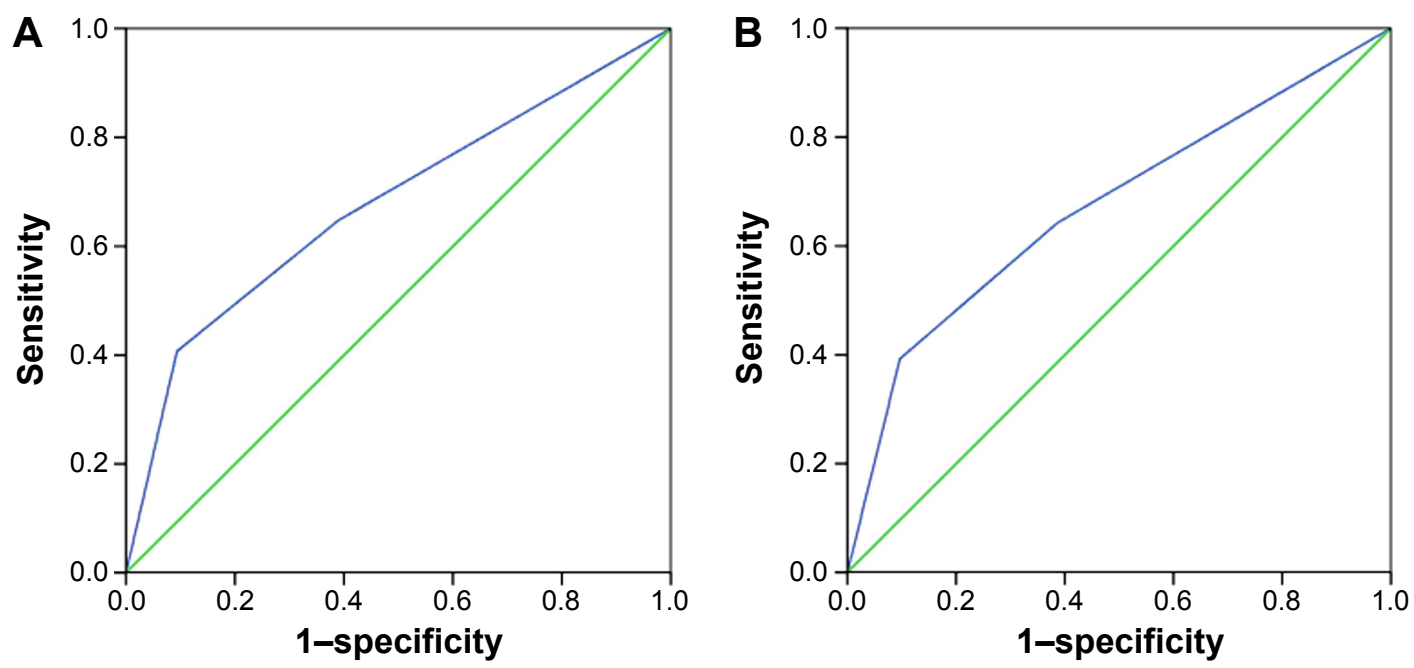

Figure I The receiver operating characteristic curve for predicting cause-specific survival (A) and overall survival (B) of patients with small-cell carcinoma of the cervix using lymph node ratio.
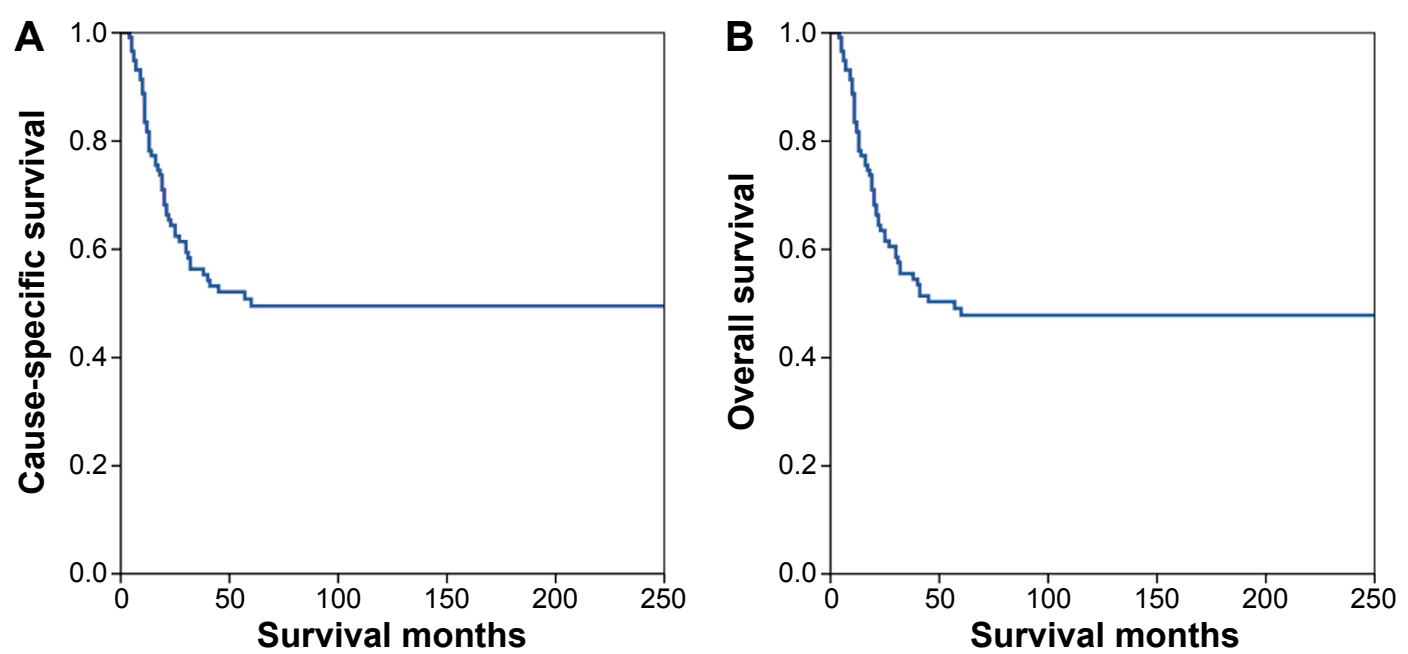

Figure 2 Cause-specific survival (A) and overall survival (B) of patients with small-cell carcinoma of the cervix.
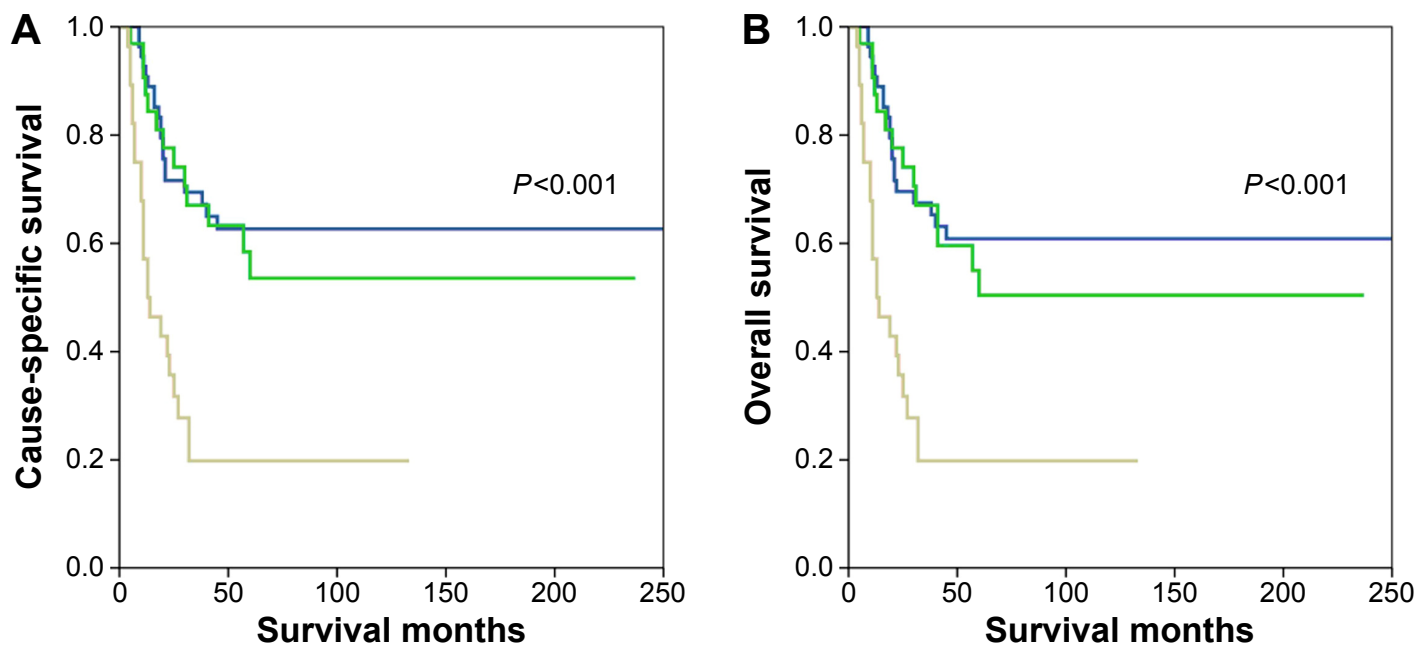

$$
\neg \mathrm{LNR}=0 \quad \neg \mathrm{LNR}=0.01-0.17-\square \mathrm{LNR}>0.17
$$

Figure 3 Cause-specific survival (A) and overall survival (B) of patients with small-cell carcinoma of the cervix with different lymph node ratio (LNR) stage. 

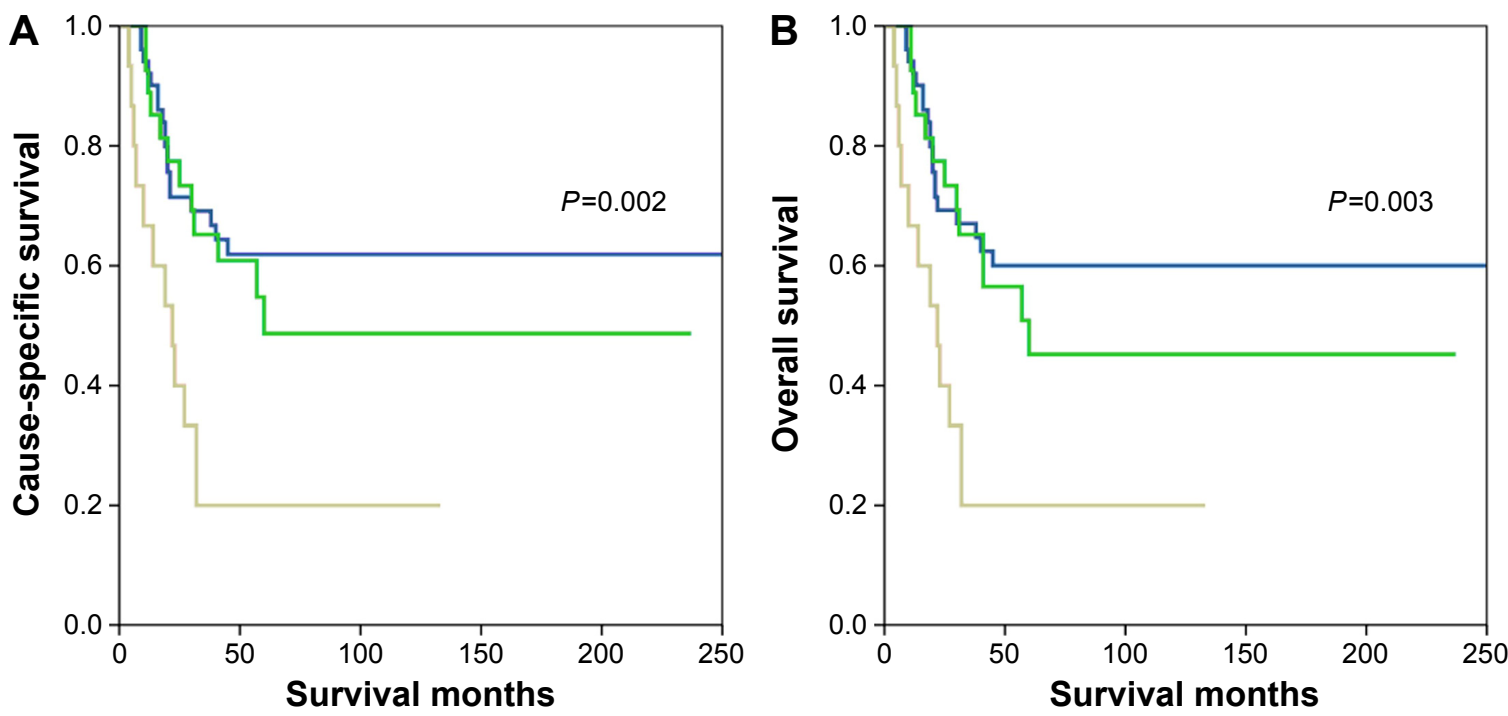

$\sim \mathrm{LNR}=0 \quad \square \mathrm{LNR}=0.01-0.17-\square \mathrm{LNR}>0.17$

Figure 4 Cause-specific survival (A) and overall survival (B) of small-cell carcinoma of the cervix patients with FIGO stage I-II according to different lymph node ratio (LNR) stage.

Abbreviation: FIGO, International Federation of Gynecology and Obstetrics.

stage III-IV patients. This difference might be due to a limited number of patients with FIGO stage III-IV $(\mathrm{N}=20)$. The 5-year survival rate in patients with early-stage SCCC was $\sim 50 \%$, which is consistent with the results of our study. ${ }^{5,7,30}$ According to our results, LNR can be used to predict those early-stage SCCC patients who are more likely to be highly aggressive and prone to metastasize.

There are, however, several limitations including the inherent biases that exist in any retrospective study. The SEER database had certain intrinsic limitations, including lack of information on pathological parameters such as depth of invasion, margin status, and lymphovascular invasion, as well as lack of information on adjuvant chemotherapy, recurrence, treatment of recurrence, and comorbidities. However, the primary strength of this study was the ability to describe the epidemiology, prognostic factors, and treatment trends in this rare type of cancer using the SEER registry. In addition, the cutoff point was obtained based on the ROC curve. Due to low incidence of SCCC and lack of literature focusing on the prognostic value of LNR in SCCC patients, identification of the optimal cutoff point for LNR still needs further study.

In conclusion, LNR appears to be useful in identifying SCCC patients with worse prognosis and it may help to individualize adjuvant therapy. However, the results of this retrospective study need to be further confirmed by future prospective studies so as to determine the category of patients who may benefit from tailored adjuvant treatment.

\section{Acknowledgments}

This work was supported by grants from the National Natural Science Foundation of China (No 81402527), the Sci-Tech Office of Guangdong Province (No 2013B021800157, 2013B021800458), the Youth Foundation of Fujian Provincial Health and Family Planning Commission (No 2014-2-63), and the Natural Science Foundation of Fujian Province (No 2015J01550).

\section{Disclosure}

The authors have no conflicts of interest to disclose in this work.

\section{References}

1. Albores-Saavedra J, Gersell D, Gilks CB, et al. Terminology of endocrine tumors of the uterine cervix: results of a workshop sponsored by the College of American Pathologists and the National Cancer Institute. Arch Pathol Lab Med. 1997;121(1):34-39.

2. Satoh T, Takei Y, Treilleux I, et al. Gynecologic Cancer InterGroup (GCIG) consensus review for small cell carcinoma of the cervix. Int J Gynecol Cancer. 2014;24(9 Suppl 3):S102-S108.

3. Gardner GJ, Reidy-Lagunes D, Gehrig PA. Neuroendocrine tumors of the gynecologic tract: a Society of Gynecologic Oncology (SGO) clinical document. Gynecol Oncol. 2011;122(1):190-198.

4. Intaraphet S, Kasatpibal N, Siriaunkgul S, Chandacham A, Sukpan K, Patumanond J. Prognostic factors for small cell neuroendocrine carcinoma of the uterine cervix: an institutional experience. Int J Gynecol Cancer. 2014;24(2):272-279.

5. Lee JM, Lee KB, Nam JH, et al. Prognostic factors in FIGO stage IB-IIA small cell neuroendocrine carcinoma of the uterine cervix treated surgically: results of a multi-center retrospective Korean study. Ann Oncol. 2008;19(2):321-326.

6. Liao LM, Zhang X, Ren YF, et al. Chromogranin A (CgA) as poor prognostic factor in patients with small cell carcinoma of the cervix: results of a retrospective study of 293 patients. PLoS One. 2012;7(4):e33674. 
7. Wang KL, Chang TC, Jung SM, et al. Primary treatment and prognostic factors of small cell neuroendocrine carcinoma of the uterine cervix: a Taiwanese Gynecologic Oncology Group study. Eur J Cancer. 2012; 48(10):1484-1494

8. Chan JK, Loizzi V, Burger RA, Rutgers J, Monk BJ. Prognostic factors in neuroendocrine small cell cervical carcinoma: a multivariate analysis. Cancer. 2003;97(3):568-574.

9. McCusker ME, Coté TR, Clegg LX, Tavassoli FJ. Endocrine tumors of the uterine cervix: incidence, demographics, and survival with comparison to squamous cell carcinoma. Gynecol Oncol. 2003;88(3): 333-339.

10. Tornesello ML, Buonaguro L, Buonaguro FM. Mutations of the TP53 gene in adenocarcinoma and squamous cell carcinoma of the cervix: a systematic review. Gynecol Oncol. 2013;128(3):442-448.

11. Polterauer S, Khalil S, Zivanovic O, et al. Prognostic value of lymph node ratio and clinicopathologic parameters in patients diagnosed with stage IIIC endometrial cancer. Obstet Gynecol. 2012;119(6): 1210-1218.

12. Ataseven B, Grimm C, Harter P, et al. Prognostic value of lymph node ratio in patients with advanced epithelial ovarian cancer. Gynecol Oncol. 2014;135(3):435-440.

13. Bachmann C, Brucker SY, Kraemer B, et al. The prognostic relevance of node metastases in optimally cytoreduced advanced ovarian cancer J Cancer Res Clin Oncol. 2015;141(8):1475-1480.

14. Metindir J, Bilir G. Impact of the ratio of metastatic to examined lymph nodes on the survival of early-stage cervical cancer patients. Onkologie. 2009;32(3):103-106.

15. Fleming ND, Frumovitz M, Schmeler KM, et al. Significance of lymph node ratio in defining risk category in node-positive early stage cervical cancer. Gynecol Oncol. 2015;136(1):48-53.

16. Polterauer S, Hefler L, Seebacher V, et al. The impact of lymph node density on survival of cervical cancer patients. Br J Cancer. 2010;103(5): 613-616.

17. Chen Y, Zhang L, Tian J, Fu X, Ren X, Hao Q. Significance of the absolute number and ratio of metastatic lymph nodes in predicting postoperative survival for the International Federation of Gynecology and Obstetrics stage IA2 to IIA cervical cancer. Int J Gynecol Cancer. 2013; 23(1):157-163.

18. Chen Y, Zhang L, Tian J, Ren X, Hao Q. Combining the negative lymph nodes count with the ratio of positive and removed lymph nodes can better predict the postoperative survival in cervical cancer patients. Cancer Cell Int. 2013;13(1):6.

19. Surveillance, Epidemiology, and End Results (SEER) Program (www. seer.cancer.gov) SEER*Stat Database: Incidence - SEER 18 Regs Research Data + Hurricane Katrina Impacted Louisiana Cases, Nov 2014 Sub (1973-2012 varying) - Linked To County Attributes - Total US, 1969-2013 Counties, National Cancer Institute, DCCPS, Surveillance Research Program, Surveillance Systems Branch, released April 2015, based on the November 2014 submission. Accessed: June 1, 2015.
20. Pecorelli S, Zigliani L, Odicino F. Revised FIGO staging for carcinoma of the cervix. Int J Gynaecol Obstet. 2009;105(2):107-108.

21. Edge SB, Byrd DR, Carducci MA, Compton CC, editors. AJCC Cancer Staging Manual. 7th ed. New York, NY: Springer; 2009.

22. Veronesi U, Zurrida S, Viale G, Galimberti V, Arnone P, Nolè F. Rethinking TNM: a breast cancer classification to guide to treatment and facilitate research. Breast J. 2009;15(3):291-295.

23. Truong PT, Woodward WA, Thames HD, Ragaz J, Olivotto IA, Buchholz TA. The ratio of positive to excised nodes identifies highrisk subsets and reduces inter-institutional differences in locoregional recurrence risk estimates in breast cancer patients with 1-3 positive nodes: an analysis of prospective data from British Columbia and the M. D. Anderson Cancer Center. Int J Radiat Oncol Biol Phys. 2007; 68(1):59-65.

24. Wei C, Deng WY, Li N, et al. Lymph node ratio as an alternative to the number of metastatic lymph nodes for the prediction of esophageal carcinoma patient survival. Dig Dis Sci. 2015;60(9): 2771-2776.

25. Wu XJ, Miao RL, Li ZY, et al. Prognostic value of metastatic lymph node ratio as an additional tool to the TNM stage system in gastric cancer. Eur J Surg Oncol. 2015;41(7):927-933.

26. Zekri J, Ahmad I, Fawzy E, et al. Lymph node ratio may predict relapse free survival and overall survival in patients with stage II \& III colorectal carcinoma. Hepatogastroenterology. 2015;62(138): 291-294.

27. Vinh-Hung V, Verkooijen HM, Fioretta G, et al. Lymph node ratio as an alternative to $\mathrm{pN}$ staging in node-positive breast cancer. J Clin Oncol. 2009;27(7):1062-1068.

28. Wu SG, He ZY, Li Q, et al. Prognostic value of metastatic axillary lymph node ratio for Chinese breast cancer patients. PLoS One. 2013; 8(4):e61410.

29. He Z, Wu S, Li Q, Lin Q, Xu J. Use of the metastatic lymph node ratio to evaluate the prognosis of esophageal cancer patients with node metastasis following radical esophagectomy. PLoS One. 2013;8(9): e73446.

30. Chen TC, Huang HJ, Wang TY, et al. Primary surgery versus primary radiation therapy for FIGO stages I-II small cell carcinoma of the uterine cervix: a retrospective Taiwanese Gynecologic Oncology Group study. Gynecol Oncol. 2015;137(3):468-473.
OncoTargets and Therapy

\section{Publish your work in this journal}

OncoTargets and Therapy is an international, peer-reviewed, open access journal focusing on the pathological basis of all cancers, potential targets for therapy and treatment protocols employed to improve the management of cancer patients. The journal also focuses on the impact of management programs and new therapeutic agents and protocols on

\section{Dovepress}

patient perspectives such as quality of life, adherence and satisfaction. The manuscript management system is completely online and includes a very quick and fair peer-review system, which is all easy to use. Visit http://www.dovepress.com/testimonials.php to read real quotes from published authors. 